\title{
Male Involvement in Family Planning Utilization and Associated Factors in Womberma District, Northern Ethiopia: Community-Based Cross-Sectional Study
}

This article was published in the following Dove Press journal: Open Access Journal of Contraception

\author{
Getinet Wondim' \\ Genet Degu ${ }^{2}$ \\ Yohannes Teka $\mathbb{D}^{2}$ \\ Gedefaw Diress $\mathbb{1 D}^{3}$ \\ 'Key Population and Partner Notification \\ Service, CDC, Woldia, Ethiopia; \\ ${ }^{2}$ Department of Midwifery, College of \\ Medicine and Health Science, Debre \\ Markos University, Debre Markos, \\ Ethiopia; ${ }^{3}$ Department of Public Health, \\ College of Health Science, Woldia \\ University, Woldia, Ethiopia
}

Background: Reproductive health issues are an inclusive concern for both men and women. In order to improve maternal health, strengthening male participation in family planning is an important public health initiative. Yet, men are still the main decisionmakers in the family in Ethiopia, especially in the rural community. There is little concrete evidence of the extent of male participation in family planning and its barriers in rural settings.

Purpose: To assess the magnitude of male involvement in family planning utilization and its associated factors in the rural community of northern Ethiopia.

Materials and Methods: A community-based cross-sectional study design was carried out on 620 currently married men. A multi-stage sampling technique was used to select the participants of the study. Data were collected using interviewer-administered structured questionnaires. Multivariable logistic regression analysis was performed to identify variables associated with male participation in family planning.

Results: In this study, only $12.5 \%$ of males were directly involved in the use of family planning using a male contraceptive method, and about $60.0 \%$ of males were involved in family planning through spousal communication and approval. Being educated $[\mathrm{AOR}=1.64$; 95\% CI: (1.12-2.62)], having an educated partner $[\mathrm{AOR}=1.77 ; 95 \% \mathrm{CI}:(1.17-2.94)]$, having a positive attitude towards family planning [AOR=2.27; 95\% CI: $(1.53-3.36)$ ], discussing with wife $[\mathrm{AOR}=2.51 ; 95 \% \mathrm{CI}$ : (1.69-3.72)] and having adequate knowledge about family planning $[\mathrm{AOR}=1.92 ; 95 \% \mathrm{CI}$ : $(1.28-2.87)]$ were positively associated with male involvement in family planning utilization whereas having more than three children $[\mathrm{AOR}=0.32 ; 95 \% \mathrm{CI}:(0.15-0.70)]$ was negatively associated with male involvement in family planning utilization.

Conclusion: In general, as compared to the national recommendation, the level of male participation in family planning utilisation was low. In order to improve male participation in family planning, improving male knowledge and attitudes towards family planning is essential.

Keywords: family planning, male involvement, contraceptive, Womberma

\section{Introduction}

In order to achieve the Sustainable Development Goals (SDGs), including reducing maternal mortality, the participation of men in reproductive health issues, including family planning, is essential. ${ }^{1,2}$ In developing countries, the promotion and
Correspondence: Gedefaw Diress Tel +251913756945

Email gedefawdiress@gmail.com 
provision of family planning can make a significant contribution to the empowerment of women and the achievement of universal primary education. In addition, family planning can reduce maternal death by $32 \%$ and child death by $10 \% .^{3-5}$ However, the rates of contraceptive use in Sub-Saharan Africa (SSA) are still low. ${ }^{6,7}$ In Africa, the opposition or non-involvement of men in family planning is one of the contributing factors for low contraceptive use or high unmet need. ${ }^{8}$

While family planning programmes have traditionally been aimed at women, there is growing awareness that reproductive wellbeing is the responsibility of both men and women. Since the 1994 International Conference on Population and Growth and the 1995 Beijing Conference, male participation in family planning has gained more consideration and attention worldwide. ${ }^{9}$ However, the programmes have not been more stressed by the majority of African countries. ${ }^{10}$

Male participation in contraceptive use improves women's uptake and continuity of family planning approaches by increasing spousal coordination and decreasing opposition. ${ }^{11-13}$ Past research has also demonstrated that male non-involvement in family planning leads to a high incidence of contraceptive discontinuation among women. ${ }^{14,15}$ Especially in SSA, like Ethiopia, men are key decision-makers in family planning.

In Ethiopia, the contraceptive prevalence rate rose from $15 \%$ in 2005 to $36 \%$ in 2016 . However, the unmet need for family planning is still high in the region $(22 \%) .{ }^{16-18}$ In Ethiopia, this high unmet demand and other factors such as lack of awareness, fear of social rejection, resistance to spouses, religious or cultural values, and concern for contraceptive side-effects lead to a high fertility rate (average 4.6 children). ${ }^{18-21}$

As mentioned in the SDGs, fostering a rapid reduction in fertility to or below the level of substitution is necessary in order to foster economic development. In reaction to these global goals, the Ethiopian Federal Ministry of Health $(\mathrm{FMoH})$ set a target for a contraception prevalence rate of $55 \%$ by $2020 .{ }^{20-22}$ However, most family planning policy initiatives in Ethiopia focus only on women. Moreover, the majority of rural women in the country have little control over their lives and are entirely dependent on their husbands. Improving male interest in family planning is also a crucial public policy intervention to achieve national and SDGs. Failure to include men in family planning services in a patriarchal community such as Ethiopia has significant repercussions, even though women are encouraged to use contraception strategies because of resistance from the spouse. ${ }^{19,22-24}$ This can also lead to a high incidence of contraceptive discontinuation. $^{14}$

Based on Ethiopian national survey results, the 12month contraceptive discontinuation rate for all methods was substantially high $(35-37 \%){ }^{19-23}$ Previous studies performed in various parts of Africa showed that male participation is mandatory to minimise contraceptive discontinuation rates. ${ }^{11-13}$ However in Ethiopia, the magnitude of male involvement in family planning was significant. ${ }^{11,25,26}$ Thus, identifying the barriers of male involvement is vital in the development and scale-up of evidence-based male-involvement family planning interventions.

In the past, few studies have recognised obstacles to male involvement in the use of family planning, but most previous studies have been performed on urban environments that vary in socio-demographic and behavioural factors from a rural environment. ${ }^{11,25,26}$ Besides, there is a dramatic difference in contraceptive prevalence and discontinuation rates between rural areas and urban areas in the 2016 Ethiopian Demographic and Health Survey (EDHS) report. ${ }^{23,27}$ However, there is little concrete knowledge of the extent of male interest in family planning and its barriers in rural settings. To address this gap, this study assessed the level of male involvement in family planning utilization and its associated factors in the rural community of northern Ethiopia. The Ethiopian Ministry of Health and other partners in intervention design and future studies will benefit from the results of this report.

\section{Materials and Methods} Study Design, Area, and Period

A community-based cross-sectional study was conducted from March to April 2017 in Womberma district, Northern part of Ethiopia. Womberma district had a total population of 127,000 of which about 24,800 were women with reproductive age group. ${ }^{28}$ It had a total of 20 health post, 5 public health centers, and 9 private clinics which were currently serving the population. ${ }^{28}$

\section{Population and Eligibility Criteria}

All currently married men who residing in Womberma district and whose partners with reproductive age group (15-49) were the source population. All married men who resided in five selected kebeles and whose partners with 
reproductive age group (15-49 years) were the study population. Men who were critically ill, unable to talk or hear during the study period, and men whose partners were beyond reproductive age, ie aged above 49 years were excluded from the study.

\section{Sample Size Determination}

The sample size was determined by using the double proportion formula, considering the following assumptions: proportion of male involvement in the exposed group $=53.3 \%$ (by selecting the support of FP use as exposure variable) from a similar study conducted in Debre Markos town, ${ }^{25}$ margin of error $(w)=5 \%$, design effect of $2,10 \%$ non-response rate, $Z \alpha / 2=1.96$ at $95 \%$ confidence interval. The final sample size was considered to be 620 .

\section{Sampling Procedure}

A multi-stage sampling technique was used to select the study participants. In Womberema District, a total of 20 kebeles (1 semi-urban and 19 rural) were found. Shindi 01 Kebele is the administrative capital of Womberema District. However, it was not found in the list of cities or towns in Ethiopia. ${ }^{30}$ So, in the current study, it is considered a semi-urban area.

First, stratification was done as semi-urban and rural, and then Shindi 01 Kebele selected deliberately and 4 rural kebeles from 19 rural kebeles were randomly selected by lottery method. Finally, the study participants were selected by a systematic random sampling method by using a Community Based Health Information System (CHIS) registration book as a sampling frame. The study participants were proportionally allocated for each kebele based on the number of married males in the kebele. The first household was selected through the lottery method followed by the selection of every other 12th household in that order. This process was continued, till the numbers of study participants were obtained from each kebeles, but if the wife of the selected household was not in range of reproductive age, the next household with reproductive age was included in the study.

\section{Study Variables and Measurements}

The main outcome variable was the level of male involvement in family planning (involved/non-involved or low involvement). The predictor variables include age, ethnicity, education level, occupation, religion, age of wife, educational status of wife, occupation of wife, income, number of living children, a desired number of children, sex preference, spousal communication, husband approval, knowledge on family planning and attitudes towards family planning.

In this study, male involvement in FP was computed from the following five "Yes" or "No" questions (1.) Do you use contraceptives currently? (2.) Do you support FP methods? (3.) Do you encourage your wife to use FP? (4.) Do you approve of contraceptive use by your wife? (5.) Do you have a desire to use FP in the future?

If the participant responded "yes" to the first question, we considered as directly involved in family planning. Furthermore, questions $2-5$ were intended to measure male involvement through spousal communication and approval about family planning. For questions $2-5$, one point was given for each "yes" response and zero point for each "no" response. An additive summary score was created and which was then dichotomized to create a binary outcome variable. Based on the summative score of the question designed to assess male involvement through spousal communication and approval, men with scores 3 and above were considered as having better involvement in FP. If men scored 0-2 from the summative score of questions, it was considered as non-involved (low involvement). ${ }^{25}$

To measure the participant's knowledge, they were asked the following five questions. 1.) Do you know about FP? (Yes/no) 2.) List benefits of FP (I do not know/one/2-3/4 or more) 3.) List FP methods (none/only one/2-3/4 and above) 4.) Do you know male FP (yes/no) 5.) Average birth interval (Immediately after delivery/6 months-1 year/1-2 years/above 2 years/I do not know). For question 1 and 4, zero point was given for "no" response and one point was given for "yes" response. For question 2, zero point was given for "I don't know", one point is given for men who listed one benefit of FP, two points were given for men who listed 2 or 3 benefits of FP and three points were given for men who listed 4 or more benefits of FP. Similarly, for question 3, zero points were given for men who did not list any contraceptives ("none"), one point is given for men who listed one FP method, two points were given for men who listed two or three types of FP methods and three points were given for men who listed four or more type of FP methods. For question 5, one point was given for the correct response (more than two years) and zero point for all other responses. Knowledge scores were summed up to give a total knowledge score for each respondent. Therefore, the total score of knowledge questions ranging from zero 
to nine was classified into two categories of response: good knowledge/poor knowledge. Male knowledge on family planning was classified as having good knowledge if men responded correctly above or equal to the mean value from knowledge assessing questions. Men who scored below mean value were considered as having poor knowledge of family planning. ${ }^{31}$

Attitude on FP was measured using 7-Likert scale items. 1.) Using condoms does not reduce men's sexual pleasure. 2.) Men sterilization (vasectomy) has no harm. 3.) Too many family sizes strain the families' economic situation 4.) Too many children make happy 5.) Too many children are often harmful to the health of the mother. 6.) Family planning practice improves trust between husband and wife. 7.) Men should share FP practice in the family. Based on these items, men who scored above or equal to the mean value of attitude assessment questions were considered as having a favorable attitude towards family planning and men who scored below the mean value were considered as having an unfavorable attitude. ${ }^{13}$

\section{Data Collection Procedure}

Data were collected using an interviewer-administered structured questionnaire. The questionnaire was adapted from similar studies ${ }^{13,29,32}$ and it was prepared initially in English language and translated to the local language (Amharic) by two secondary and high school English teachers and one health officer. The data were collected by trained secondary school completed personnel during the weekends and holidays because this was the optimal time to get study participants at home. If the participant was not available during data collection, repeated visits were done to minimize non-response bias. The owner of the household was selected in households where more than one married man was presented.

To assure the quality of the data, 2-day long training was given to both data collectors and supervisors on objective, relevance, and purpose of the study. The questioner was reviewed by one researcher who is an expert on reproductive health research and agreed that the tool is a valid measure of male involvement. Besides, two experts (researchers) reviewed all of the questionnaire items for readability, clarity, and comprehensiveness and came to some level of agreement as to which items should be included in the final questionnaire. The reliability of the questioner was done using the pre-test technique. A pretest was done on $5 \%$ of the total sample size randomly selected men from Burafer kebele a week before the actual time of data collection. The pre-test checked on the answerability, sequence, and appropriateness of questions. The data collected from the pre-test were analyzed using SPSS and the reliability coefficient (alpha) was 0.82 which implies acceptable reliability. The supervisors and the researcher were closely following the day to day data collection process to complete the data collection. Confusing or inconsistent conditions were rechecked and corrected before entering the data into a computer.

\section{Data Analysis}

Participant characteristics were summarized using frequency and percentages for categorical variables. Mean values ( \pm standard deviation $(\mathrm{SD})$ ) were used to describe the continuous type of data. Multivariable logistic regression was used to identify factors contributing to male involvement. Variables with a p-value of less than 0.2 at bivariable analysis were entered into the final logistic regression model to control possible confounders. The odds ratio of the final model and their 95\% confidence intervals were used as measures of association between the predictors and outcome variable. A p-value of less or equal to 0.05 was considered statistically significant. All analyses were performed using SPSS version 20.

\section{Ethical Consideration}

The study was conducted following the Declaration of Helsinki. Initially, ethical clearance was obtained from Debre Markos University's ethical review committee (Reference number: DMU/RCS/064/2017). Then, the detailed purpose of the study was explained to all study participants and written informed consent was taken from every participant. All information collected from the respondents was treated as confidential in that no name was recorded on the questionnaire and the collected data were kept using a computer password.

\section{Result}

\section{Socio-Demographic and Reproductive Health Characteristics}

A total of 620 married men were included in the study. The mean age of participants was $32( \pm 8 \mathrm{SD})$ years. The majority $(90.6 \%)$ of participants were Amhara by ethnic group and 93\% of participants were Orthodox Christian by religion. Nearly $44.0 \%$ of participants and more than half $(53.0 \%)$ of their partners could not read and write (Table 1). 
Table I Sociodemographic Characteristics of the Respondents in Relation to Male Involvement in Womberma Woreda in 2017

\begin{tabular}{|c|c|c|c|c|c|c|}
\hline \multirow[t]{3}{*}{ Variables } & \multirow[t]{3}{*}{ Category } & \multirow{3}{*}{$\begin{array}{l}\text { Overall } \\
\text { Frequency (\%) }\end{array}$} & \multicolumn{4}{|c|}{ Male Involvement } \\
\hline & & & \multicolumn{2}{|l|}{ Yes } & \multicolumn{2}{|l|}{ No } \\
\hline & & & $\mathbf{N}$ & $\%$ & $\mathbf{N}$ & $\%$ \\
\hline \multirow[t]{3}{*}{ Ethnicity } & Amhara & $562(90.6)$ & 343 & 92.7 & 219 & 87.6 \\
\hline & Oromo & $45(7.3)$ & 20 & 5.4 & 25 & 10.0 \\
\hline & Others $^{\mathrm{a}}$ & $13(2.1)$ & 7 & 1.9 & 6 & 2.4 \\
\hline \multirow[t]{4}{*}{ Age } & $20-29$ & $134(2 \mid .6)$ & 104 & 7.8 & 30 & 1.2 \\
\hline & $30-39$ & $293(47.3)$ & 185 & 29.5 & 108 & 20.8 \\
\hline & $40-49$ & $138(22.3)$ & 61 & 8.6 & 77 & 16.4 \\
\hline & $\geq 50$ years & $55(8.9)$ & 20 & 5.4 & 35 & 14.0 \\
\hline \multirow[t]{3}{*}{ Religion } & Orthodox & $576(92.9)$ & 352 & 95.1 & 224 & 89.6 \\
\hline & Muslim & $37(6.0)$ & 14 & 3.8 & 23 & 9.2 \\
\hline & Others $^{b}$ & $7(1.1)$ & 4 & I.I & 3 & 1.2 \\
\hline \multirow[t]{5}{*}{ Educational status } & Unable to read and write & $272(43.9)$ & 117 & 31.6 & 155 & 62.0 \\
\hline & Informal education & $86(13.9)$ & 51 & 13.8 & 35 & 14.0 \\
\hline & Primary & $181(29.2)$ & 128 & 34.6 & 53 & 21.2 \\
\hline & Secondary & $46(7.4)$ & 40 & 10.8 & 6( & 2.4 \\
\hline & Higher & $35(5.6)$ & 34 & 9.2 & I & 0.4 \\
\hline
\end{tabular}

Notes: $\mathrm{N}=$ frequency; \%=percentage; ${ }^{\mathrm{a}}$ Includes Gumez, Agew; ${ }^{\mathrm{b}}$ Protestant, Catholic.

More than half of the participants $(52.7 \%)$ desired to have 3-4 children and nearly $34.0 \%$ of men wanted to have more than five children at the end of reproductive life. Of all participants, $58.4 \%$ of men had good knowledge of family planning. About $54.0 \%$ of men have ever discussed FP methods with their partners (Table 2).

\section{Male Involvement Through Family Planning Utilization}

In this study, from a total of 620 married men, only 50 men $12.5 \%$ (95\% CI; 8.4-15.9) used male FP methods. Of 50 men who used FP method, 49 used condoms as family planning methods and the remaining one participant used the withdrawal method. The reason mentioned for not use of family planning was not known and did not know the source of FP, the need for more children, and fear of side effects (Figure 1.)

\section{Male Involvement Through Spousal Communication and Approval About Family Planning}

In the current study, nearly $60.0 \%$ of men were involved in family planning through spousal communication and approval. Among all respondents, more than half (54.0\%) of men have never discussed FP with their partner. The majority $(61.5 \%)$ of men encouraged their partners to use family planning utilization. On the other hand, nearly twothirds (64.7\%) of men supported the use of FP methods of their partners/wives. Similarly, $62.0 \%$ of men approved of family planning use. Regarding decision-making on family planning, nearly $10.0 \%$ of men make a decision them self's and $81.0 \%$ decide with their partner.

\section{Men's Knowledge of FP Methods}

About $79.4 \%$ of the respondents knew about family planning and familiar with at least one method. More than half (56\%) of men were able to list two to three family planning methods. But only $25.0 \%$ of them were aware of male family planning methods. Regarding the recommended birth interval, one-third of men reported less than 2 years. In general, only $58.4 \%$ of men had good knowledge of FP (Figure 2).

\section{Attitude of Men on Family Planning}

About half (49.2\%) of men disagreed that condom use does not decrease sexual pleasure and nearly $40.0 \%$ of men disagreed on vasectomy do not harm individuals. One-fifth $(20.2 \%)$ of men disagreed on too many children constrain the family economy. In general more than half (52.1\%) of men have an unfavorable attitude towards family planning methods. 
Table 2 Reproductive Characteristics of Respondents in Relation to Male Involvement in Womberma Woreda in 2017

\begin{tabular}{|c|c|c|c|c|c|c|}
\hline \multirow[t]{3}{*}{ Variables } & \multirow[t]{3}{*}{ Category } & \multirow{3}{*}{$\begin{array}{l}\text { Overall } \\
\mathbf{n}(\%)\end{array}$} & \multicolumn{4}{|c|}{ Male Involvement } \\
\hline & & & \multicolumn{2}{|l|}{ Yes } & \multicolumn{2}{|l|}{ No } \\
\hline & & & $\mathbf{N}$ & $\%$ & $\mathbf{N}$ & $\%$ \\
\hline \multirow[t]{4}{*}{ Number of living children } & No child & $92(14.8)$ & 82 & 22.2 & 10 & 4.0 \\
\hline & $\mathrm{I}-2$ & $216(34.8)$ & $15 \mid$ & 40.8 & 65 & 26.0 \\
\hline & $3-4$ & $194(31.3)$ & 103 & 27.8 & 91 & 36.4 \\
\hline & $\geq 5$ & $118(19.1)$ & 34 & 9.2 & 84 & 33.6 \\
\hline \multirow[t]{3}{*}{ Number of desired children } & $1-2$ & $83(13.4)$ & 67 & 18.1 & 16 & 6.4 \\
\hline & $3-4$ & $327(52.7)$ & 219 & 59.2 & 108 & 43.2 \\
\hline & $\geq 5$ & $210(33.9)$ & 84 & 22.7 & 126 & 50.4 \\
\hline \multirow[t]{2}{*}{ FP Knowledge level } & Good knowledge & $362(58.4)$ & 261 & 70.5 & 101 & 40.4 \\
\hline & Poor knowledge & $258(4 I .6)$ & 109 & 29.5 & 149 & 59.6 \\
\hline \multirow[t]{2}{*}{ Ever discussed FP } & Yes & $285(46.0)$ & 220 & 59.5 & 65 & 26.0 \\
\hline & No & $335(54.0)$ & 150 & 40.5 & 185 & 74.0 \\
\hline \multirow[t]{3}{*}{ Decision-maker family planning } & My self & $60(9.7)$ & 16 & 4.3 & 44 & 17.6 \\
\hline & My wife & $58(9.3)$ & 30 & 8.1 & 28 & 11.2 \\
\hline & Both & $502(81.0)$ & 324 & 87.6 & 178 & 71.2 \\
\hline
\end{tabular}

\section{Factors Associated with Male} Involvement in Family Planning Utilization During \multivariable analysis, level of education, partners' level of education, number of living children, attitude on FP, knowledge on FP, and discussion on FP with wife were significantly associated with male involvement (Table 3).
Men's level of education was positively associated with male involvement in family planning. Men who attended formal education were 2 times $(\mathrm{AOR}=1.64 ; 95 \% \mathrm{CI}$ : 1.124-2.624) more likely to be involved in family planning as compared to noneducated men. Similarly, men who have educated partners had $77 \%$ higher odds of being involved in family planning utilization

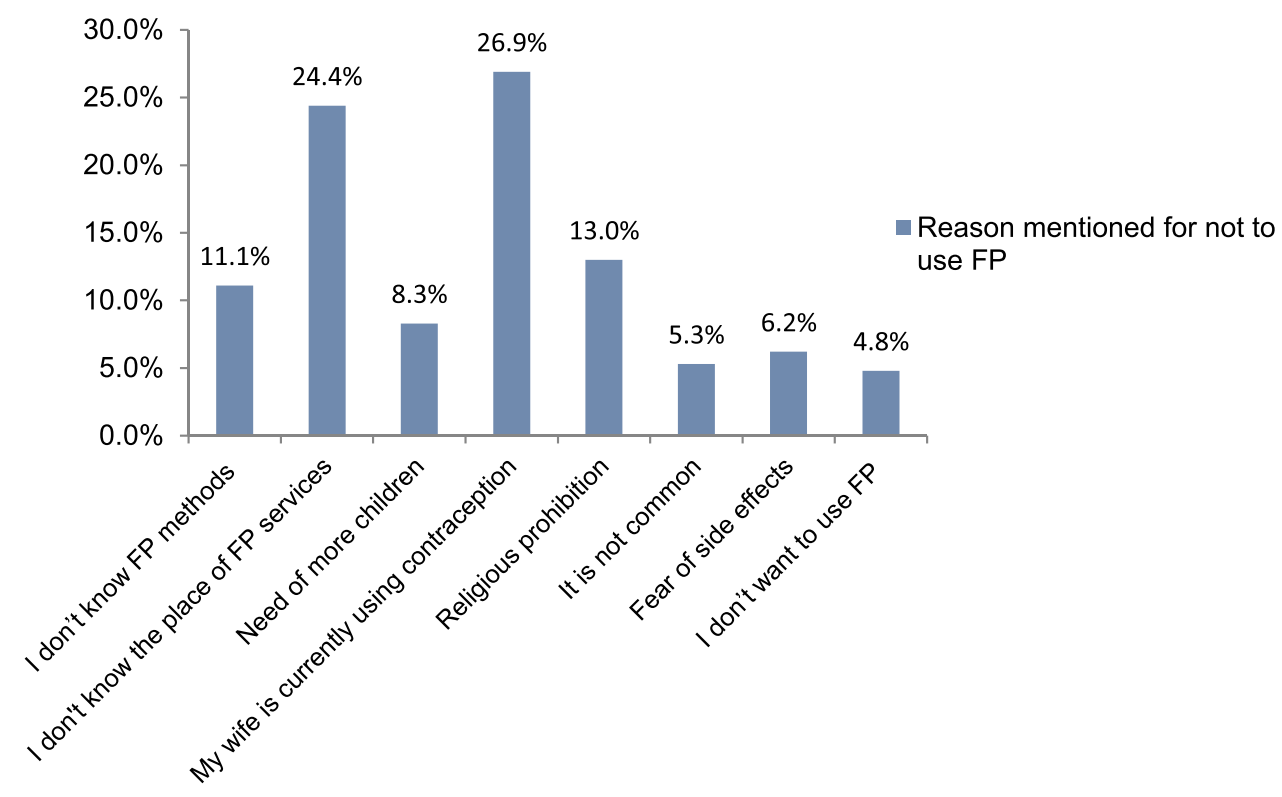

Figure I Reason for not using FP methods in Womberma district, Northern Ethiopia. 


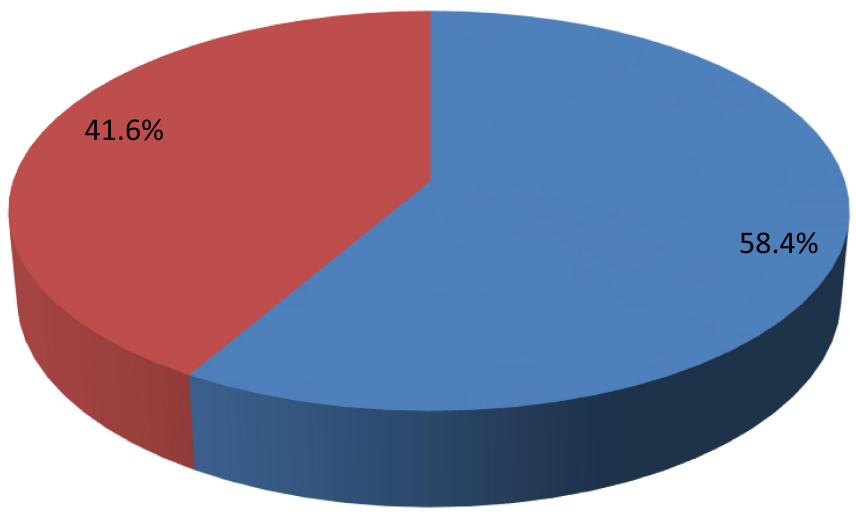

Good Knowledge

- Poor Knowledge

Figure 2 Men's level of knowledge on FP in Womberma District, Northern Ethiopia.

(AOR=1.77; 95\% CI: 1.167-2.943) than their counterparts. Men with a favorable attitude towards family planning were approximately 2 times more likely to be involved in family planning than those having an unfavorable attitude $(\mathrm{AOR}=2.27 ; 95 \% \mathrm{CI}$ : 1.533-3.356). Number of living children is also significantly associated with male involvement. Men who have five and more children had a $68 \%$ reduction in the odds of involvement in family planning utilization than those who have no children (AOR $=0.32$; 95\% CI: 0.147-0.702). Similarly, men who had good knowledge of family planning were 2 times more likely involved in family planning utilization $[\mathrm{AOR}=1.92 ; 95 \% \mathrm{CI}$ :
(1.284-2.867)] than those who have poor knowledge. Men who were ever discussed with wife were 2.51 times more likely to be involved than those who do not discuss.

\section{Discussion}

In the rural community of Ethiopia, where men are family decision-makers and women have little influence over their problem of reproductive health, ${ }^{26,33}$ it is important to determine the extent of male engagement in the use of family planning. This analysis measured the magnitude of various degrees of male participation in the use of family planning and its factors in a rural region of northern

Table 3 Multivariable Analysis of Male Involvement in Womberma District, 2017

\begin{tabular}{|c|c|c|c|c|}
\hline Variables & Category & COR $(95 \% \mathrm{Cl})$ & AOR $(95 \% \mathrm{Cl})$ & P-value \\
\hline Educational status & $\begin{array}{l}\text { Non-educated } \\
\text { Educated }\end{array}$ & $\begin{array}{l}\text { Ref. } \\
3.81(2669-5.431)^{*}\end{array}$ & $\begin{array}{l}\text { Ref. } \\
\text { I.64(I.124-2.624)* }\end{array}$ & 0.04 \\
\hline Educational status of wife & $\begin{array}{l}\text { Non-educated } \\
\text { Educated }\end{array}$ & $\begin{array}{l}\text { Ref. } \\
4.80(3.283-7.043)^{* *}\end{array}$ & $\begin{array}{l}\text { Ref. } \\
\text { I.77(1.167-2.943)* }\end{array}$ & 0.027 \\
\hline Attitude on FP & $\begin{array}{l}\text { Positive } \\
\text { Negative }\end{array}$ & $\begin{array}{l}2.68(1.920-3.743)^{*} \\
\text { Ref. }\end{array}$ & $\begin{array}{l}2.27(1.533-3.356)^{* *} \\
\text { Ref. }\end{array}$ & 0.001 \\
\hline Number of living children & $\begin{array}{l}\text { No child } \\
\mathrm{I}-2 \\
3-4 \\
\geq 5\end{array}$ & $\begin{array}{l}\text { Ref } \\
0.28(0.138-0.58 I) \\
0.14(0.068-0.282)^{*} \\
0.05(0.023-0.106)^{*}\end{array}$ & $\begin{array}{l}\text { Ref } \\
0.49(0.229-1.067) \\
0.32(0.147-0.702)^{* *} \\
0.17(0.071-0.388)^{* *}\end{array}$ & $\begin{array}{l}0.073 \\
0.004 \\
0.001\end{array}$ \\
\hline Ever discussion & $\begin{array}{l}\text { Yes } \\
\text { No }\end{array}$ & $\begin{array}{l}4.17(2.940-5.927)^{* *} \\
\text { Ref. }\end{array}$ & $\begin{array}{l}\text { 2. } 5 \mathrm{I}(\mathrm{I} .692-3.722)^{* *} \\
\text { Ref. }\end{array}$ & 0.001 \\
\hline FP knowledge level & $\begin{array}{l}\text { Good } \\
\text { Poor }\end{array}$ & $\begin{array}{l}3.53(2.52 I-4.950)^{*} \\
\text { Ref. }\end{array}$ & $\begin{array}{l}\text { I.92 (1.284-2.867)* } \\
\text { Ref. }\end{array}$ & 0.016 \\
\hline
\end{tabular}

Notes: ${ }^{*} p<0.05 ;{ }^{* *} p<0.01$; Ref., Reference. 
Ethiopia. The results of this research found that only $12.5 \%$ of men were involved on their own by using strategies of family planning. This is comparable to the previous studies done in Ethiopia and Kenya, ${ }^{25,34}$ but far lower than a recent survey of $40.0 \%$ in $\operatorname{Uganda}^{35}$ and $71.0 \%$ in India. ${ }^{36}$ Surprisingly, $99.0 \%$ of males used only condoms in this survey of men who used contraception, suggesting that the use of other forms of male contraceptive methods was exceedingly poor. This might be related to the limited choice of available male contraceptives in the rural community. Therefore, efforts towards familiarizing permanent family planning for those who are absolutely sure do not want children in the future should be strengthened.

Male interest in family planning went beyond the use of methods of contraception. ${ }^{37,38}$ Male participation was also measured in the current study by spousal communication and approval. The result showed that through spousal communication and approval, more than half of men were engaged in family planning. Studies conducted in Kenya ${ }^{39}$ and Cameroon ${ }^{17}$ confirm this, but it was higher than a study conducted in Bahir Dar, northern Ethiopia, where $25.5 \%$ of men were interested in FP. ${ }^{40}$ The potential reason for the variability of the outcome is the operationalization of male involvement. The concept of male involvement differs significantly across the research. The interpretation of the findings should also be carried out with caution.

Evidence has shown that husband approval of family planning contributes to progress in women's contraceptive use. ${ }^{41}$ In this survey, $61.5 \%$ of men encourage and endorse the use of family planning and almost $63.0 \%$ of men support the form of family planning that is higher than a study conducted in Debre Markos, Ethiopia. ${ }^{25}$ In the current study, although only $12.5 \%$ of respondents used contraceptive methods, more than two-thirds $(67.7 \%)$ of men have a desire to use contraceptive methods in the future.

The finding of the current study showed that more than half of men have a negative attitude towards family planning and surprisingly nearly one-fourth of men agreed that males should not share the family planning method. This might contribute to the low contraceptive prevalence rate in the rural community of Ethiopia. A significant number of men in Africa seemed resistant to accept the use of FP for financial and religious reasons. ${ }^{13,25,42}$ A study done in Tanzania indicated that men were feared that women would be unfaithful if allowed to use contraception. Men believed that condoms were useful for the prevention of
HIV/AIDS with prostitutes and did not associate use with FP. $^{34,43}$ Therefore, the finding in this study implied that the need to introduce accurate information to address negative attitudes towards the contraceptive method.

To improve the utilization of reproductive health programs including family planning identifying barriers and facilitators of male involvement is fundamental. Several important factors emerge from the study which should be considered for future interventions. The first determinant of male involvement was the level of education of husband and partner. In agreement with previous studies done in different parts of Africa, ${ }^{17,44}$ the finding of this study showed that the higher educational status of the husband and his partner was positively associated with male involvement in family planning. The possible explanation is related to educated men will more likely to have good knowledge of family planning which initiates them to involve in family planning. Moreover, educated women may initiate their partner to discuss family planning and reproductive health issue which might encourage the male to be involved in family planning. ${ }^{17}$ Thus, the achievement of at least primary education for both sexes is an important intervention to improve the level of male involvement in family planning.

Second, the number of children was the other factor that was identified as a determinant of male involvement in this study. Previous studies indicated that families who had more children enhanced male involvement. ${ }^{39}$ Unexpectedly, in the current study, men who had three and more children were less likely to be involved in family planning than those who have no child. The discrepancy should be assessed with a strong study design in the future.

The third key determinant of male involvement was knowledge about FP. Good knowledge about family planning methods was positively associated with male involvement in family planning as similar to past pieces of evidence. ${ }^{17,31}$ Men who know various family planning methods, particularly male contraceptive options, might directly involve in family planning utilization. The increasing trend in all these studies may indicate the fact that knowledge of family planning is pre-request for male involvement in family planning utilization. However, in this study, a significant number of men $(41.6 \%)$ had poor knowledge of FP.

The fourth factor that was associated with male involvement was attitudes towards family planning. Men's positive attitude towards family planning is a facilitator for male involvement in family planning in this study. 
However, only $47.9 \%$ of men had a positive attitude in the current study. This finding implies that more than half of men should change their attitude towards family planning.

The last determinant of male involvement was a discussion between couples about family planning. One of the key barriers to the unmet need for family planning was women's perceptions of husbands' opposition. Thus, a discussion between couples is fundamental for reproductive health and family planning use. It increases up taking and continuation of contraceptive use. ${ }^{11,12}$ The current study also showed that discussion between couples about family planning increases the probability of male involvement in family planning. Open discussion promotes the chance of joint decisions on family size which then enhances male involvement. But in this study, only $46 \%$ of men discussed with their partner about family planning.

The main strength of the current study was involving both semi-urban and rural men which improve the generalizability of the finding. Secondly, the response rate was $100 \%$. But the study had also several limitations. First, since the study was cross-sectional it does not show a causal relationship between factors and outcome of interest. Second, social desirability bias could be introduced because of the use of the interviewer-administered type of data collection tool.

\section{Conclusions}

To conclude, just $12.5 \%$ of men use family planning methods themselves explicitly. However, by means of spousal communication and approval, more than half of the men in the Womberma district were participated in family planning. Husband and partner educational status, number of living children, male approach to family planning, male family planning awareness, and conversation with the wife about family planning have been described as factors associated with male engagement in family planning. In Ethiopia, comprehensive health education initiatives should be made to shift derogatory attitudes to family planning and increase the level of awareness relevant to family planning. Therefore, through mobilising and designing educational programmes, city leaders, social workers, public and non-governmental organisations must come together and build awareness. Finally, to determine triggers for a pessimistic mindset, studies should be conducted using a qualitative sample design.

\section{Abbreviation}

AOR, adjusted odds ratio; COR, crude odds ratio; FP, family planning.

\section{Data Sharing Statement}

The data can be available from the corresponding author.

\section{Ethical Approval and Consent to Participate}

The study was conducted following the Declaration of Helsinki. Initially, ethical clearance was obtained from Debre Markos University's ethical review committee (Reference number: DMU/RCS/064/2017). The detailed purpose of the study was explained to all study participants and written informed consent was taken from every participant. All information collected from the respondents was treated as confidential in that no name was recorded on the questionnaire and the collected data were kept using a computer password.

\section{Author Contributions}

All authors made substantial contributions to conception and design, acquisition of data, or analysis and interpretation of data; took part in drafting the article or revising it critically for important intellectual content; agreed to submit to the current journal; gave final approval of the version to be published; and agree to be accountable for all aspects of the work.

\section{Funding}

There is no funding to report.

\section{Disclosure}

The authors declare that they have no competing interests.

\section{References}

1. Akrinnola B, Susheela S. Couple's fertility and contraception decision making in developing countries. Int Fam Plan Perspect. 1998;24 (1): $18-40$.

2. Doyle MW, Stiglitz JE. Eliminating extreme inequality: A sustainable development goal, 2015-2030. Ethics Int Aff. 2014;28(1):5-13. doi:10.1017/S0892679414000021

3. Mutowo J, Kasu CM, Mufunda E. Women empowerment and practices regarding use of dual protection among family planning clients in urban Zimbabwe. Pan Af Med j. 2014;17:300. doi:10.11604/ pamj.2014.17.300.3282

4. Tilahun T, Coene G, Temmerman M, Degomme O. Spousal discordance on fertility preference and its effect on contraceptive practice among married couples in Jimma zone, Ethiopia. Reprod Health. 2014;11(1):27. doi:10.1186/1742-4755-11-27

5. Bongaarts J, Cleland J, Townsend J, Bertrand J, Gupta M. Family Planning Programs For the 21ST Century. NewYork: Population Council. 2012.

6. Agbo. HA, Ogbonna. C, Bn O. Factors related to the uptake of contraceptive in a rural community in Plateau State Nigeria: A cross-sectional community study. J Med Tropics. 2013;15(2):107. doi:10.4103/2276-7096.123583 
7. Alex E, Anibal F, Anna G, Jolene I. Family Planning: The Unfinished Agenda, the Lancet Sexual and Reproductive Health Series. WHO; 2006.

8. Ethiopian Demographic Health Surevy (EDHS). Centeral Stastical Agencey; 2011.

9. UNICEF \& World Health Organization. WHO/UNICEF Joint Monitoring Programme for Water Supply, Sanitation and Hygiene (JMP); 2017.

10. Male TL. Involvement in FP, a Review of Selected Programme Initiatives in Africa. Washington DC: Academy for Educational Development; 1996.

11. Adera. A, Belete T, Gebru. A, Hagos. A. Assessment of the role of men in FP utilization at, Tigray, North Ethiopia. Am J Nurs Sci. 2015;4(4):174.

12. Mishra EA, Nanda P, Speizer IS, Calhoun LM, Zimmerman A, Bhardwaj R. Men's attitudes on gender equality and their contraceptive use in Uttar Pradesh, India. Reproductive-Health. 2014;11(1). doi:10.1186/1742-4755-11-41

13. Bayray A. Assessment of male involvement in FP use among men in south eastern zone of Tigray, Ethiopia. Scholarly J Med. 2012;1:125.

14. Zakaria M, Bhuiyan MM. Determinants of male involvement in women's reproductive health: a multilevel study in bangladesh. Malaysian J Public Health Med. 2016;16(3):211-218.

15. Nte A, Odu N, Enyindah C. Male involvement in family planning: women's perception. Niger J Clin Pract. 2009;12:3.

16. Sezer K. Influence of age on the usage of family planning methods by Turkish married men living in southeastern Turkey. Turkish $\mathrm{J}$ Med Sci. 2013;2:14.

17. Egbe T, Ketchen S, Egbe E, Ekane G. Risk Factors and Barriers to Male Involvement in the Choice of Family Planning Methods in the Buea Health District. South West Region: Cameroon Women Health; 2016.

18. Pompili M, Lester D, Innamorati M, et al. Quality of life and suicide risk in patients with diabetes mellitus. Psychosomatics. 2009;50 (1):16-23. doi:10.1176/appi.psy.50.1.16

19. Bassett ML, Halliday JW, Ferris RA, Powell LW. Diagnosis of hemochromatosis in young subjects: predictive accuracy of biochemical screening tests. Gastroenterology. 1984;87(3):628-633. doi:10.1016/0016-5085(84)90536-5

20. Alter MJ, Kruszon-Moran D, Nainan OV, et al. The prevalence of hepatitis C virus infection in the United States, 1988 through 1994. New Eng j Med. 1999;341(8):556-562. doi:10.1056/NEJM199908193410802

21. Kebede A, Abaya SG, Merdassa E, Bekuma TT. Factors affecting demand for modern contraceptives among currently married reproductive age women in rural Kebeles of Nunu Kumba district, Oromia, Ethiopia. Contraception Reproduct Med. 2019;4(1):21. doi:10.1186/s40834-019-0103-3

22. Sustainable Development Goals. A report by the Leadership Council of the Sustainable Development Solutions Network. Available from http://www.unsdsn.org/. 2014.

23. Central Statistical Agency. Ethiopia Demographic and Health Survey 2016. Addis Ababa, Ethiopia and Calverton, Maryland, USA: Central Statistical Agency, Ethiopia and ICF; 2016.

24. Dral AA, Tolani MR, Smet E. Factors Influencing Male Involvement in Family Planning in Ntchisi District, Malawi - A Qualitative Study. Afr J Reprod Health. 2018;22:4.

25. Kassa M, Abajobir AA, Gedefaw. M. Level of male involvement and associated factors in family planning services utilization among married men in Debremarkos town, Northwest Ethiopia. BMC Int Health Hum Rights. 2014;14:33.

26. Demissie DB, Kurke AT, Awel A, Male KO. Involvement in Family Planning and Associated Factors among Marriedin Malegedo Town West Shoa Zone, Oromia, Ethiopia. planning. 2016;15. J Culture Soc Dev. 2016;15.
27. Central Statistical Agency. Demographic Health Survey 2011. Addis Ababa, Ethiopia and Calverton, Maryland, USA; 2011.

28. Malenganisho W, Magnussen P, Vennervald B, et al. Intake of Alcoholic Beverages Is a Predictor of Iron Status and Hemoglobin in Adult Tanzanians. J Nutr. 2007;137(9):2140-2146. doi:10.1093/jn/137.9.2140

29. Kassa M, Alemu AA, Gedefaw M. Level of male involvement and associated factors in family planning services utilization among married men in Debremarkos town, Northwest Ethiopia. BMC Int Health Hum Rights. 2014;14(1). doi:10.1186/s12914-014-0033-8

30. Central Statistics Agency (Ethiopia). "Population and Household Census Ethiopia 2007. Region Amhara; 2017.

31. Dereje BD. Male Involvement in fp and associated factors among married in malegedo Town West Shoa Zone, Oromia, Ethiopia. J Culture Soc Dev. 2016;1:45.

32. Tuloro T, Deressa W, Ali A. The role of men in contraceptive use and fertility preference in Hossana town, southern Ethiopia. Ethiop $J$ Health Dev. 2006:2;458.

33. Adera A, Belete T, Gebru A, Hagos A, Gebregziabher W. Assessment of the Role of Men in Family Planning Utilization at Edaga-Hamuse Town, Tigray, North Ethiopia. Am J Nurs Sci. 2015;4(4):174. doi:10.11648/j.ajns.20150404.15

34. Butto D, Mburu S. Factors Associated with Male Involvement in Family Planning in West Pokot County, Kenya. Univ J Public Health. 2015;3(4):160-168. doi:10.13189/ujph.2015.030404

35. Dougherty A, Kayongo A, Deans S, et al. Knowledge and use of family planning among men in rural Uganda. BMC Public Health. 2018;18(1):1294. doi:10.1186/s12889-018-6173-3

36. Rekha T, Unnikrishnan B, Prasanna PM, Nithin Kumar RH, Vishal Raina HH. Married men's involvement in family planning-A study from coastal Southern India. J Clin Diagnostic Res. 2015;9(4):LC04.

37. Ijadunola MY, Abiona TC, Ijadunola KT, Afolabi OT, Esimai OA, OlaOlorun FM. Male involvement in family planning decision making in Ile-Ife, Osun State, Nigeria. Afr J Reprod Health. 2010;14:4.

38. Vouking MZ, Evina CD, Tadenfok CN. Male involvement in family planning decision making in sub-Saharan Africa-what the evidence suggests. Pan Afr Med J. 2014;19.

39. Dennis B, Factors MS. Associated with male involvement in fp in west pokot County, Kenya Universal. J Public Health (Bangkok). 2015;2:12547.

40. Yeshareg W, Zelalem A, Liles S. The current states of male involvement on family planning and factors correlated with among male factory workers in Bahir Dar City, Ethiopia. Am J Public Health Res. 2014;2(6):232-238. doi:10.12691/ajphr-2-6-3

41. Vouking MZ, Evina CD, CN. T. Male involvement in family planning decision making in sub-Saharan Africa-what the evidence suggests. Pan Afr Med J. 2014;19.

42. Eleuthera M, Ankomah Augustine RP. Attitudes of men towards family planning in mbeya region, tanzania: a rural-urban comparison of qualitative data. J Biosoc Sci. 1998;30:3.

43. Demissie. DB. Male Involvement in Family Planning and Associated Factors among Marriedin Malegedo Town West Shoa Zone, Oromia, Ethiopia. Psychology. 2016.

44. Macellina Y, Titilayo C, Kayode T. Male involvement in family planning decision making in ile-ife, osun State, Nigeria. Afr $J$ Reprod Health. 2010;2:154. 
Open Access Journal of Contraception

Dovepress

\section{Publish your work in this journal}

Open Access Journal of Contraception is an international, peerreviewed, open access, online journal, publishing original research, reports, reviews and commentaries on all areas of contraception. In addition to clinical research, demographics and health-related aspects, the journal welcomes new findings in animal and preclinical

Submit your manuscript here: http://www.dovepress.com/open-access-journal-of-contraception-journ studies relating to understanding the biological mechanisms and practical development of new contraceptive agents. The manuscript management system is completely online and includes a very quick and fair peer-review system. Visit http://www.dovepress.com/testimonials. php to read real quotes from published authors. 